in vivo $31: 285-290(2017)$

doi:10.21873/invivo.11057

Review

\title{
Factors Associated with Microalbuminuria Remission in Patients with Type 2 Diabetes: Importance of Early Intervention for Microalbuminuric Patients (TSUGARU STUDY)
}

\author{
NORIO NAKAMURA ${ }^{1,2}$, IKUYO NARITA ${ }^{2}$, TAKESHI FUJITA ${ }^{2}$, REIICHI MURAKAMI ${ }^{2}$, \\ MICHIKO SHIMADA ${ }^{2}$, MASAYUKI NAKAMURA ${ }^{2}$, \\ HIROSHI OSAWA ${ }^{3}$, HIDEAKI YAMABE ${ }^{2}$ and KEN OKUMURA ${ }^{2}$ \\ for THE DIABETIC NEPHROPATHY TREATMENT STUDY GROUP
}

${ }^{1}$ Community Medicine, Hirosaki University Graduate School of Medicine, Aomori, Japan;

${ }^{2}$ Department of Cardiology and Nephrology, Hirosaki University Graduate School of Medicine, Aomori, Japan;

${ }^{3}$ Department of General Medicine, Hirosaki University Hospital, Aomori, Japan

\begin{abstract}
Aim: The aim of this study was to clarify the rates of remission and progression for microalbuminuria in patients with type 2 diabetes (T2DM); and factors associated with remission and progression of diabetic nephropathy (DN). Patients and Methods: T2DM patients with a urinary albumin excretion (UAE) rate of $30-300 \mathrm{mg} / \mathrm{gCr}$ who were attending the medical clinic in the Tsugaru region in Japan were enrolled into this prospective, observational study for 36 months $(N=317)$. We investigated the rate of remission (UAE $<30 \mathrm{mg} / \mathrm{g}$ creatinine (Cr); normal albuminuria) and the rate of progression (UAE $\geq 300 \mathrm{mg} / \mathrm{gCr}$; overt proteinuria) 36 months after study registration. Results: The number of patients whose UAE levels were $<30 \mathrm{mg} / \mathrm{gCr}$ (DN remission) at 36 months after registration was 64 (27.4\%), and the number of patients whose UAE levels were $\geq 300$ $\mathrm{mg} / \mathrm{gCr}$ (DN progression) at 36 months after registration was $32(13.7 \%)$. From multiple logistic regression analysis, the sole factor that contributed to remission at 36 months after registration was the UAE levels at registration (OR: 0.99; 95\% CI: 0.98-1.00, $p=0.003)$, and the factors that
\end{abstract}

This article is freely accessible online.

Correspondence to: Norio Nakamura, MD, Ph.D., Community Medicine, Hirosaki University Graduate School of Medicine, 5 Zaifu-cho, Hirosaki-city, Aomori 036-8562, Japan. Tel: +81 172395057, Fax: +81 172359190, e-mail: nnakamur@r2.dion.ne.jp

Key Words: Diabetic nephropathy, microalbuminuria, urinary albumin excretion (UAE). contributed to progression at 36 months after registration were the levels of UAE (OR: 1.01; 95\% CI: 1.01-1.02, $p=0.000)$ and systolic blood pressure (OR: 0.96; 95\% CI: 0.93-1.00, $p=0.033)$ at registration. Conclusion: Results suggest that patients with less severe microalbuminuria among microalbuminuric patients might more commonly experience $D N$ remission and that earlier intervention is very important for promoting microalbuminuria remission in $D N$.

Diabetic nephropathy (DN) is the leading cause of end-stage renal failure in patients with type 2 diabetes mellitus, and its prevalence is increasing annually worldwide. Compared to 20 years ago, the incidence of diabetic complications without DN has decreased; however, DN is still the main complication in diabetes (1). On the other hand, high incidences of $\mathrm{DN}$ in type 2 diabetic patients have been reported, at $40-60 \%(2,3)$. Further $\mathrm{DN}$ is a strong risk factor for atherosclerosis and cardiovascular disease compared to chronic kidney disease without diabetes (4). Additionally, at present, patients with end-stage DN in Japan comprise over $40 \%$ of the patients starting dialysis therapy in one year (5).

Therefore, if we could prevent DN progression, we could be able to consequently prevent the need for dialysis in these patients. Unfortunately, an effective treatment strategy has not yet been developed for DN. According to recent studies, the early detection and treatment of $\mathrm{DN}$, including measuring urinary albumin excretion (UAE), the strict control of blood sugar, blood pressure and treatment for other risks (multifactorial intervention), are considered very important (69). However, it is unclear whether such procedure/treatment is actually routinely performed. 
Thus, the aim of the present study was to clarify whether multifactorial intervention was actually performed. Because we were investigating the change of albuminuria in patients with $\mathrm{DN}$, we assessed the remission and progression rates of microalbuminuria using a 36-month follow-up survey.

\section{Patients and Methods}

Study design and procedure. Type 2 diabetes patients with a UAE of $30-300 \mathrm{mg} / \mathrm{g}$ creatinine $(\mathrm{Cr})$ who were attending the medical clinic in the Tsugaru region of Aomori district Japan were enrolled in this study after giving their written informed consent. Each medical clinic sent the study registration data [verification of age, gender, diabetes duration, medication, UAE, systolic and diastolic $\mathrm{BP}$, pulse rate, blood urea nitrogen (BUN), creatinine (Cr), sodium $(\mathrm{Na})$, potassium $(\mathrm{K})$, chloride $(\mathrm{Cl})$, uric acid $(\mathrm{UA}), \mathrm{BS}$, and $\left.\mathrm{Hb}_{\mathrm{A} 1 \mathrm{C}}\right]$ to the study office by facsimile. Complete registration was confirmed at the office. Similarly, follow-up data (UAE, systolic and diastolic $\mathrm{BP}$, pulse rate, $\mathrm{BUN}, \mathrm{Cr}, \mathrm{Na}, \mathrm{K}, \mathrm{Cl}, \mathrm{UA}, \mathrm{BS}$, and $\mathrm{Hb}_{\mathrm{A} 1 \mathrm{C}}$ ) were obtained 36 months after registration.

Because we were expecting increased awareness about DN in the clinic in this region during the study, we added comments regarding the current standard management of DN at registration (Treatment Guide for Diabetes 2010-2011) (10).

We investigated the rate of remission (UAE $<30 \mathrm{mg} / \mathrm{gCr}$; normal albuminuria) and the rate of progression (UAE $\geq 300 \mathrm{mg} / \mathrm{gCr}$; overt proteinuria) at 36 months after registration. In addition, we investigated the factors contributing to remission or progression in this study.

The present study was approved by the Ethical Review Board of Hirosaki University Graduate School of Medicine. The study was carried out on receiving their written informed consent after providing with the information about the study. This study was registered with the University Hospital Medical Information Network Clinical Trials Registry (no. UMIN000022124).

Statistical analysis. The data are expressed as the mean \pm SD. The data obtained at registration and at 36 months after registration were compared by a paired $t$-test. Comparison of the data among three groups (normal albuminuria, microalbuminuria, and overt proteinuria) at 36 months after registration was analysed with Bonferroni's adjustment after one-way ANOVA. To investigate the factors contributing to remission or progression, a relative odds ratio was calculated using multiple logistic regression analysis. $p<0.05$ was considered statistically significant.

\section{Results}

Three hundred and seventeen patients were enrolled in this study, and 234 (74.5\%) patients were followed-up for 36 months after registration. The data obtained at registration are shown in Table I.

The changes in BP and blood analysis between registration and 36 months after registration are shown in Table II. The levels of UAE, BUN, $\mathrm{Cr}, \mathrm{K}$ and UA had increased significantly 36 months after registration. The systolic and diastolic BP had decreased significantly 36 months after registration.
The number of patients whose levels of UAE were $<30 \mathrm{mg} / \mathrm{gCr}$ (DN remission) at 36 months after registration was $64(27.4 \%)$ and the number of patients whose levels of UAE were $\geq 300 \mathrm{mg} / \mathrm{gCr}$ (DN progression) at 36 months after registration was $32(13.7 \%)$.

Comparison of data at registration and 36 months after registration among the three groups (remission [normal albuminuria], microalbuminuria and progression [overt proteinuria]) are shown in Table III. At registration, the levels of UAE in the progression group were significantly higher than those in the remission and microalbuminuria groups. At registration, the levels of $\mathrm{K}$ in the remission group were significantly lower than those in the microalbuminuria group. At registration, the levels of $\mathrm{HbA} 1 \mathrm{C}$ in the remission group were significantly lower than those in the microalbuminuria and progression groups.

On the other hand, at 36 months after registration, the levels of $\mathrm{Na}$ in the remission group were significantly higher than those in the progression group. Furthermore, the levels of $\mathrm{HbA} 1 \mathrm{C}$ in the remission group were also significantly lower than those in the progression group.

In addition, the differences in the data obtained at registration and 36 months after registration among the three groups are shown in Table IV. The BS levels in the remission group were significantly lower than those in the progression group. The frequency of use of dipeptidyl peptidase (DPP)4 inhibitors in the remission and microalbuminuria groups had significantly increased at 36 months after registration compared with that at registration. There was no increase in the frequency of DPP-4 inhibitor use in the progression group over the 36 months.

The relative odds ratios (OR) of the factors associated with the remission and progression of microalbuminuria as assessed using multiple logistic regression analysis are shown in Table V. From this analysis, the sole factor that contributed to remission at 36 months after registration was the levels of UAE at registration (OR: 0.99; 95\% CI: $0.98-$ $1.00, p=0.003$ ), and the factors that contributed to progression at 36 months after registration were the levels of UAE (OR: 1.01; 95\% CI: 1.01-1.02, $p=0.000$ ) and systolic BP (OR: 0.96 ; 95\% CI: 0.93-1.00, $p=0.033$ ) at registration.

\section{Discussion}

We showed that the levels of UAE significantly increased over 36 months in an observational study of 234 patients with stage $2 \mathrm{DN}$. This may be why there was a large increase in the UAE levels in some individuals between registration and 36 months post-registration, as the progression rate was $13.7 \%$, which did not seem to be that high. Additionally, this may be another reason why the levels of UAE had increased in many of the patients in the microalbuminuria group. The levels of BUN, Cr, K and UA had significantly increased 36 
Table I. Demographic and clinical data.

\begin{tabular}{lccrr}
\hline Characteristics & $\mathrm{n}$ & Mean \pm SD & Min & Max \\
\hline Age (years) & 234 & $69.3 \pm 9.3$ & 42 & 89 \\
Gender (male) & 234 & $53.8 \%$ & 126 & \\
Duration of diabetes (months) & 231 & $118.8 \pm 92.7$ & 0 & 578 \\
UAE (mg/gCr) & 234 & $100.3 \pm 69.1$ & 30 & 291 \\
BUN (mg/dl) & 230 & $16.7 \pm 5.0$ & 6 & 35 \\
Creatinine (mg/dl) & 234 & $0.73 \pm 0.24$ & 0.20 & 1.61 \\
Na (mEq/l) & 220 & $141.3 \pm 2.4$ & 133 & 147 \\
K (mEq/l) & 221 & $4.2 \pm 0.4$ & 3 & 5.4 \\
UA (mg/dl) & 230 & $5.1 \pm 1.3$ & 2.5 & 12 \\
Blood sugar (mg/dl) & 234 & $159.2 \pm 58.4$ & 72 & 467 \\
Hb A1C (\%) & 234 & $7.1 \pm 1.0$ & 5.0 & 10.3 \\
(mmol/mol) & 234 & $53.8 \pm 7.6$ & 31.0 & 88.6 \\
& & & & \\
SBP (mmHg) & 233 & $144.6 \pm 19.8$ & 101 & 235 \\
DBP (mmHg) & 233 & $78.8 \pm 13.4$ & 47 & 123 \\
Pulse rate (/min) & 213 & $78.4 \pm 12.0$ & 56 & 124 \\
& & & & \\
RASi & 234 & $67.5 \%$ & 158 & \\
Statin & 234 & $32.1 \%$ & 75 & \\
DPP4i & 234 & $34.2 \%$ & 80 & \\
\hline
\end{tabular}

DPP4i: Dipeptidyl peptidase-4 inhibitor, RASi: renin-angiotensin system inhibitor, UAE: urinary albumin excretion.

months after registration; this might be because of the gradual progression of DN over the 36 months and the increased use of renin-angiotensin system (RAS) inhibitors. The systolic and diastolic BP significantly decreased over the 36 months; this might be because of the increased use of RAS inhibitors and increased antihypertensive therapy.

We investigated the changes in the use of RAS inhibitors, statins, and DPP-4 inhibitors during this study. Between registration and 36 months after registration, the use of RAS inhibitors increased from $67.5 \%$ to $73.5 \%$, the use of statins increased from $32.1 \%$ to $38.0 \%$, and the use of DPP-4 inhibitors increased form $34.2 \%$ to $53.0 \%$. The increased use of these drugs could be attributed to the additional comments about the current standard management of $\mathrm{DN}$ at registration from the study office. Although this study was not an interventional study, these results suggest that the clinicians in the region gradually gained more knowledge on the diagnosis and management of DN throughout the duration of this study.

Compared to the results from several studies which that showed the rate of microalbuminuria remission in $\mathrm{DN}(8,11$ 16), the rate found in the present study, $27.4 \%$, was not very high. Most of the contributors in this study were general physicians, not diabetes specialists, many previous papers on DN were reported from diabetic specialist faculties, such as, university hospitals or diabetic centers $(8,11-16)$. Consequently, our results in this study might accurately reflect the situation of actual clinical practice.
Table II. Comparison between the data obtained at registration and 36 months after registration.

\begin{tabular}{|c|c|c|c|c|}
\hline \multirow[b]{2}{*}{ Variables } & \multirow{2}{*}{$\begin{array}{l}\text { Registration } \\
\text { Mean } \pm \text { SD }\end{array}$} & \multicolumn{2}{|c|}{$\begin{array}{l}36 \text { months after } \\
\text { registration }\end{array}$} & \multirow[b]{2}{*}{$p$-Value } \\
\hline & & & Mean \pm SD & \\
\hline $\mathrm{UAE}(\mathrm{mg} / \mathrm{gCr})$ & $100.3 \pm 69.1$ & & $170.4 \pm 282.5$ & $<0.001$ \\
\hline BUN (mg/dl) & $16.7 \pm 5.0$ & & $17.7 \pm 5.6$ & 0.002 \\
\hline Creatinine $(\mathrm{mg} / \mathrm{dl})$ & $0.73 \pm 0.24$ & & $0.81 \pm 0.32$ & $<0.001$ \\
\hline $\mathrm{Na}(\mathrm{mEq} / \mathrm{l})$ & $141.3 \pm 2.4$ & & $141.4 \pm 2.8$ & 0.32 \\
\hline $\mathrm{K}(\mathrm{mEq} / \mathrm{l})$ & $4.2 \pm 0.4$ & & $4.3 \pm 0.5$ & 0.005 \\
\hline $\mathrm{UA}(\mathrm{mEq} / \mathrm{l})$ & $5.1 \pm 1.3$ & & $5.4 \pm 1.3$ & $<0.001$ \\
\hline Blood sugar $(\mathrm{mg} / \mathrm{dl})$ & $159.2 \pm 58.4$ & & $163.5 \pm 57.3$ & 0.32 \\
\hline $\mathrm{Hb}_{\mathrm{AlC}}(\%)$ & $7.1 \pm 1.0$ & & $7.0 \pm 1.0$ & 0.34 \\
\hline$(\mathrm{mmol} / \mathrm{mol})$ & $53.8 \pm 7.6$ & & $53.0 \pm 7.6$ & \\
\hline $\mathrm{SBP}(\mathrm{mmHg})$ & $144.6 \pm 19.8$ & & $140.4 \pm 19.5$ & $<0.001$ \\
\hline $\mathrm{DBP}(\mathrm{mmHg})$ & $78.8 \pm 13.4$ & & $74.8 \pm 12.8$ & $<0.001$ \\
\hline \multicolumn{5}{|l|}{ Medication } \\
\hline RASi & 158 & $67.5 \%$ & 172 & $73.5 \%$ \\
\hline Statin & 75 & $32.1 \%$ & 89 & $38.0 \%$ \\
\hline DPP-4i & 80 & $34.2 \%$ & 124 & $53.0 \%$ \\
\hline
\end{tabular}

Many of the variables employ the paired $t$-test to evaluate the mean difference between matched data. DPP4i: dipeptidyl peptidase-4 inhibitor, RASi: renin-angiotensin system inhibitor, UAE: urinary albumin excretion.

As shown in Table III, the levels of UAE, $\mathrm{K}$ and $\mathrm{Hb}_{\mathrm{A} 1 \mathrm{C}}$ at registration were significantly different among the remission, microalbuminuria and progression groups. When the levels of $\mathrm{UAE}$ at registration are low, remission may be more likely after 36 months, and early onset of low UAE could be interrupted as a higher likelihood of microalbuminuria remission. Similarly, good control of BS at registration might be interrupted as a higher likelihood of remission. The levels of $\mathrm{Na}, \mathrm{BS}$ and $\mathrm{Hb}_{\mathrm{AlC}} 36$ months after registration were significantly different among the remission, microalbuminuria and progression groups. The control of BS 36 months after registration in the remission group was significantly better than that in the progression group. These results suggest that strict control of BS might contribute to microalbuminuria remission 36 months after registration. These results were similar to those of precious reports $(8,14,16)$.

As shown in Table V, the sole factor that contributed to remission at 36 months after registration was the levels of $\mathrm{UAE}$ at registration. The results suggest that the strict control of the UAE levels is very important. Recently, it was reported that DPP-4 inhibitors and sodium glucose cotransporter (SGLT)-2 inhibitors decreases albuminuria in patients with DN $(17,18)$. Consequently, the early intervention, example, the use of RAS inhibitors, DPP-4 
in vivo $31: 285-290(2017)$

Table III. Comparison of data among the three groups (normal, microalbuminuria and overt proteinuria).

\begin{tabular}{|c|c|c|c|c|}
\hline & $\begin{array}{l}\text { Normal albuminuria } \\
\qquad \mathrm{N}=64\end{array}$ & $\begin{array}{l}\text { Microalbuminuria } \\
\qquad \mathrm{N}=138\end{array}$ & $\begin{array}{l}\text { Overt proteinuria } \\
\qquad \mathrm{N}=32\end{array}$ & \\
\hline & Mean \pm SD & Mean \pm SD & Mean \pm SD & $p$-Value \\
\hline \multicolumn{5}{|l|}{ Study registration } \\
\hline Age (years) & $70.4 \pm 8.3$ & $68.9 \pm 9.9$ & $68.4 \pm 8.9$ & 0.49 \\
\hline Gender (male) & $27.4 \% \quad 32$ & $59 \% 73$ & 13.7521 & 0.33 \\
\hline Duration of DM (months) & $99.9 \pm 85.0$ & $122.6 \pm 85.0$ & $140.6 \pm 128.6$ & 0.10 \\
\hline RASi & $62.5 \% 40$ & $68.1 \% 94$ & $75.0 \% 24$ & 0.46 \\
\hline Statin & $31.3 \% 20$ & $31.2 \% 43$ & $37.5 \% 12$ & 0.78 \\
\hline DPP4i & $37.5 \% 24$ & $33.3 \% 46$ & $31.3 \% 10$ & 0.79 \\
\hline $\mathrm{UAE}(\mathrm{mg} / \mathrm{gCr})$ & $69.1 \pm 49.2^{\S}$ & $99.4 \pm 66.3^{*}$, & $166.4 \pm 70.9$ & $<0.001$ \\
\hline $\mathrm{BUN}(\mathrm{mg} / \mathrm{dl})$ & $15.9 \pm 4.9$ & $17.1 \pm 4.8$ & $16.7 \pm 5.9$ & 0.29 \\
\hline Creatinine (mg/dl) & $0.70 \pm 0.21$ & $0.72 \pm 0.24$ & $0.80 \pm 0.29$ & 0.13 \\
\hline $\mathrm{Na}(\mathrm{mEq} / \mathrm{l})$ & $141.4 \pm 2.7 \Pi$ & $141.2 \pm 2.3$ & $141.1 \pm 2.2$ & 0.73 \\
\hline $\mathrm{K}(\mathrm{mEq} / \mathrm{l})$ & $4.1 \pm 0.4$ & $4.2 \pm 0.4^{\dagger}$ & $4.2 \pm 0.5$ & 0.031 \\
\hline $\mathrm{UA}(\mathrm{mg} / \mathrm{dl})$ & $4.9 \pm 1.5$ & $5.2 \pm 1.3$ & $5.3 \pm 1.2$ & 0.34 \\
\hline Blood sugar (mg/dl) & $153.4 \pm 50.1^{\S}$ & $162.1 \pm 65.6$ & $158.1 \pm 37.7$ & 0.75 \\
\hline $\mathrm{Hb}_{\mathrm{A} 1 \mathrm{C}}(\%)$ & $6.8 \pm 0.9^{\S}$ & $7.2 \pm 1.0^{\dagger}$ & $7.2 \pm 1.0$ & 0.021 \\
\hline$(\mathrm{mmol} / \mathrm{mol})$ & $47.6 \pm 5.6^{\S}$ & $54.5 \pm 7.6^{\dagger}$ & $54.5 \pm 7.6$ & \\
\hline Systolic BP & $143.0 \pm 20.1$ & $146.9 \pm 19.8$ & $137.7 \pm 18.1$ & 0.05 \\
\hline Diastolic BP & $79.4 \pm 14.6$ & $79.2 \pm 13.2$ & $76.0 \pm 11.9$ & 0.43 \\
\hline \multicolumn{5}{|l|}{ Follow-up at $36 \mathrm{M}$} \\
\hline RASi & $71.9 \% 46$ & $73.2 \% 101$ & $78.1 \% 25$ & 0.8 \\
\hline Statin & $40.6 \% 26$ & $37.7 \% 52$ & $34.4 \% 11$ & 0.831 \\
\hline DPP4i & $57.8 \% 37$ & $52.9 \% 73$ & $40.6 \% 13$ & 0.28 \\
\hline $\mathrm{UAE}(\mathrm{mg} / \mathrm{gCr})$ & $17.2 \pm 7.1^{\S}$ & $108.7 \pm 71.5^{*, \ddagger}$ & $742.6 \pm 416.9$ & $<0.001$ \\
\hline $\mathrm{BUN}(\mathrm{mg} / \mathrm{dl})$ & $18.0 \pm 5.8$ & $17.4 \pm 4.6$ & $18.6 \pm 8.6$ & 0.98 \\
\hline Creatinine $(\mathrm{mg} / \mathrm{dl})$ & $0.81 \pm 0.30$ & $0.79 \pm 0.30$ & $0.89 \pm 0.42$ & 0.51 \\
\hline $\mathrm{Na}(\mathrm{mEq} / \mathrm{l})$ & $141.9 \pm 2.5^{\Pi}$ & $141.5 \pm 2.8$ & $140.3 \pm 2.9$ & 0.036 \\
\hline $\mathrm{K}(\mathrm{mEq} / \mathrm{l})$ & $4.2 \pm 0.5$ & $4.3 \pm 0.4$ & $4.3 \pm 0.5$ & 0.79 \\
\hline $\mathrm{UA}(\mathrm{mg} / \mathrm{dl})$ & $5.4 \pm 1.4$ & $5.4 \pm 1.3$ & $5.4 \pm 1.4$ & 0.99 \\
\hline Blood sugar $(\mathrm{mg} / \mathrm{dl})$ & $149.7 \pm 57.4^{\S}$ & $163.5 \pm 56.0$ & $191.0 \pm 54.8$ & 0.004 \\
\hline $\mathrm{Hb}_{\mathrm{A} 1 \mathrm{C}}(\%)$ & $6.7 \pm 0.8^{\S}$ & $7.0 \pm 1.0$ & $7.4 \pm 1.3$ & 0.011 \\
\hline$(\mathrm{mmol} / \mathrm{mol})$ & $50.7 \pm 5.0^{\S}$ & $53.0 \pm 7.6$ & $56.0 \pm 8.1$ & \\
\hline Systolic BP & $140.0 \pm 20.1$ & $140.7 \pm 19.3$ & $140.3 \pm 19.4$ & 0.97 \\
\hline Diastolic BP & $72.7 \pm 11.1$ & $75.4 \pm 13.2$ & $76.3 \pm 14.2$ & 0.31 \\
\hline
\end{tabular}

The data were analyzed by Bonferroni’s adjustment after one-way ANOVA. *Microalbuminuria $v s$. normal albuminuria, $p<0.01$. $\dagger^{\dagger}$ Microalbuminuria $v s$. normal albuminuria, $p<0.05$. ${ }^{*}$ Microalbuminuria $v s$. overt proteinuria, $p<0.01$. ${ }^{\S}$ Normal albuminuria $v s$. overt proteinuria, $p<0.01$. $\Pi_{\text {Normal }}$ albuminuria $v s$. overt proteinuria, $p<0.05$. DPP4i: dipeptidyl peptidase-4 inhibitor, RASi: renin-angiotensin system inhibitor, UAE: urinary albumin excretion.

inhibitors and/or SGLT-2 inhibitors might be effective for promoting microalbuminuria remission.

In conclusion, we showed that $27.4 \%$ and $13.7 \%$ of diabetic patients with microalbuminuria experienced remission and progression, respectively, over the course of 36 months. The sole factor that contributed to remission was the UAE levels at registration, and the factors that contributed to progression were the UAE levels and systolic $\mathrm{BP}$ at registration. These results suggest that patients with less severe microalbuminuria among microalbuminuric patients might be more likely to experience DN remission and that early intervention is very important for promoting microalbuminuria remission in DN.

\section{Conflicts of Interest}

The Authors declare that there is no conflict of interest associated with the manuscript.

\section{Acknowledgements}

The Authors would like to thank the members of Diabetic Nephropathy Treatment Study Group. They were as follows: Dr. Takako Moriyama, Dr. Miyuki Yanagimachi, Dr. Jun Matsui and Dr. Makoto Daimon (Department of Endocrinology and Metabolism, Hirosaki University Graduate School of Medicine), Dr. Shinsaku Fukuda (Community Medicine, Hirosaki University Graduate School of Medicine), Dr. Takashi Itsukaichi (Itsukaichi Naika 
Nakamura et al: Microalbuminuria Remission in Diabetes

Table IV. Comparison of data obtained at study registration and 36 months after registration.

\begin{tabular}{|c|c|c|c|c|c|c|c|c|c|c|c|}
\hline & \multicolumn{3}{|c|}{$\begin{array}{l}\text { Normal albuminuria } \\
\qquad \mathrm{N}=64\end{array}$} & \multicolumn{4}{|c|}{$\begin{array}{l}\text { Microalbuminuria } \\
\quad \mathrm{N}=138\end{array}$} & \multicolumn{3}{|c|}{$\begin{array}{l}\text { Overt proteinuria } \\
\qquad \mathrm{N}=32\end{array}$} & \multirow[b]{3}{*}{$p$-Value } \\
\hline & \multirow{2}{*}{$\begin{array}{c}\text { Difference } \\
\text { Mean }\end{array}$} & \multicolumn{2}{|c|}{$95 \% \mathrm{CI}$} & \multirow{2}{*}{$\begin{array}{c}\text { Difference } \\
\text { Mean }\end{array}$} & \multicolumn{3}{|c|}{$95 \% \mathrm{CI}$} & \multirow{2}{*}{$\begin{array}{c}\text { Difference } \\
\text { Mean }\end{array}$} & \multicolumn{2}{|c|}{$95 \% \mathrm{CI}$} & \\
\hline & & Min & Max & & Min & & Max & & Min & Max & \\
\hline \multicolumn{12}{|c|}{ Follow-up at 36 months } \\
\hline UAE & -51.9 & -64.3 & -39.4 J,$\S$ & 9.30 & -4.2 & & $22.8 \div$ & 576.18 & 421.4 & 730.9 J & $<0.001$ \\
\hline BUN & 2.22 & 0.86 & 3.58 & 0.46 & -0.36 & & 1.28 & 1.84 & -0.84 & 4.55 & 0.05 \\
\hline Creatinine & 0.12 & 0.07 & 0.17 & 0.06 & 0.04 & & 0.09 & 0.09 & -0.03 & 0.21 & 0.023 \\
\hline $\mathrm{Na}$ & 0.48 & -0.42 & 1.37 & 0.28 & -0.15 & & 0.71 & -0.72 & -1.52 & 0.09 & 0.07 \\
\hline K & 0.15 & 0.04 & 0.27 & 0.04 & -0.03 & & 0.12 & 0.09 & -0.03 & 0.21 & 0.24 \\
\hline UA & 0.48 & 0.18 & 0.79 & 0.22 & 0.04 & & 0.40 J & 0.11 & -0.36 & 0.58 & 0.22 \\
\hline BS & -3.72 & -22.1 & $14.7^{\S}$ & 1.44 & -9.3 & & $12.2^{\ddagger}$ & 32.88 & 11.5 & $54.2^{J}$ & 0.029 \\
\hline $\operatorname{HbA1C}(\%)$ & -0.07 & -0.30 & 0.16 & -0.14 & -0.33 & & 0.05 & 0.28 & -0.14 & 0.69 & 0.14 \\
\hline$(\mathrm{mmol} / \mathrm{mol})$ & -0.43 & -1.86 & 0.99 & -0.87 & -2.05 & & 0.31 & 1.74 & -0.87 & 4.28 & 0.14 \\
\hline Systolic BP & -3.06 & -9.49 & 3.37 & -6.32 & -9.6 & & $-3.01^{\text {I }}$ & 2.63 & -3.00 & 8.25 & 0.09 \\
\hline \multirow[t]{3}{*}{ Diastolic BP } & -6.63 & -10.18 & -3.07 & -3.83 & -6.04 & & $-1.62^{\mathrm{J}}$ & -0.28 & -4.01 & 4.57 & 0.05 \\
\hline & Difference & \multicolumn{2}{|c|}{$95 \% \mathrm{CI}$} & Difference & \multicolumn{3}{|c|}{$95 \% \mathrm{CI}$} & Difference & \multicolumn{2}{|c|}{$95 \% \mathrm{CI}$} & \\
\hline & Percentage & Min & Max & Percentage & Min & - & Max & Percentage & Min & $\operatorname{Max}$ & \\
\hline RASi & 9.38 & -6.81 & $-\quad 25.56$ & 5.07 & -5.66 & - & 15.8 & 3.13 & -17.62 & 23.87 & 0.58 \\
\hline Statin & 9.38 & -7.17 & $-\quad 25.92$ & 6.52 & -4.66 & - & 17.71 & -3.13 & -26.62 & 20.37 & 0.97 \\
\hline DPP4i & 20.31 & 3.37 & - $\quad 37.26 \#$ & 19.57 & 8.11 & - & $31.02^{\mathbb{J}}$ & 9.38 & -14.02 & 32.77 & 0.45 \\
\hline
\end{tabular}

The data were analyzed by Bonferroni’s adjustment after one-way ANOVA. *Microalbuminuria $v s$. normal albuminuria, $p<0.01$. ${ }^{\dagger}$ Microalbuminuria $v s$. normal albuminuria, $p<0.05$. $\$$ Microalbuminuria $v s$. overt proteinuria, $p<0.01$. \$Normal albuminuria $v s$. overt proteinuria, $p<0.01$. $\Pi_{N}$ ormal albuminuria $v s$. overt proteinuria, $p<0.05$. IStudy registration $v s$. follow-up at 36 months, $p<0.01$. "Study registration $v s$. follow-up at 36 months, $p<0.05$. DPP4i: Dipeptidyl peptidase-4 inhibitor, RASi: renin-angiotensin system inhibitor, UAE: urinary albumin excretion.

Table V. The relative odds ratios of the factors associated with remission and progression of microalbuminuria as assessed using multiple logistic regression analysis.

\begin{tabular}{|c|c|c|c|c|c|c|c|c|c|c|}
\hline & \multicolumn{5}{|c|}{ Normal albuminuria } & \multicolumn{5}{|c|}{ Overt proteinuria } \\
\hline & \multirow[b]{2}{*}{ RRR } & \multirow[b]{2}{*}{ SE } & \multirow[b]{2}{*}{$p$-Value } & \multicolumn{2}{|c|}{$95 \% \mathrm{CI}$} & \multirow[b]{2}{*}{ RRR } & \multirow[b]{2}{*}{ SE } & \multirow[b]{2}{*}{$p$-Value } & \multicolumn{2}{|c|}{$95 \% \mathrm{CI}$} \\
\hline & & & & Min & $\operatorname{Max}$ & & & & Min & $\operatorname{Max}$ \\
\hline Gender & 1.30 & 0.56 & 0.55 & 0.56 & 3.00 & 1.10 & 0.67 & 0.88 & 0.33 & 3.66 \\
\hline Age & 1.02 & 0.02 & 0.47 & 0.97 & 1.06 & 1.01 & 0.03 & 0.65 & 0.96 & 1.07 \\
\hline Duration of DM & 1.00 & 0.00 & 0.28 & 0.99 & 1.00 & 1.00 & 0.00 & 0.16 & 1.00 & 1.01 \\
\hline UAE & 0.99 & 0.00 & 0.003 & 0.98 & 1.00 & 1.01 & 0.00 & 0.000 & 1.01 & 1.02 \\
\hline BUN & 0.98 & 0.04 & 0.57 & 0.90 & 1.06 & 0.97 & 0.05 & 0.53 & 0.86 & 1.08 \\
\hline Creatinine & 0.85 & 0.90 & 0.88 & 0.11 & 6.73 & 1.68 & 2.18 & 0.69 & 0.13 & 21.40 \\
\hline $\mathrm{K}$ & 0.42 & 0.21 & 0.09 & 0.16 & 1.13 & 0.51 & 0.34 & 0.31 & 0.14 & 1.8 \\
\hline $\mathrm{Na}$ & 1.01 & 0.08 & 0.86 & 0.87 & 1.19 & 0.86 & 0.09 & 0.16 & 0.70 & 1.06 \\
\hline UA & 0.99 & 0.15 & 0.97 & 0.74 & 1.33 & 0.94 & 0.18 & 0.77 & 0.65 & 1.38 \\
\hline BS & 1.00 & 0.00 & 0.86 & 0.99 & 1.01 & 1.00 & 0.00 & 0.34 & 0.99 & 1.00 \\
\hline $\mathrm{HbA} 1 \mathrm{C}$ & 0.67 & 0.19 & 0.15 & 0.39 & 1.15 & 1.05 & 0.33 & 0.87 & 0.57 & 1.93 \\
\hline Systolic BP & 0.98 & 0.01 & 0.15 & 0.96 & 1.01 & 0.96 & 0.02 & 0.033 & 0.93 & 1.00 \\
\hline Diastolic BP & 1.02 & 0.02 & 0.23 & 0.99 & 1.06 & 1.01 & 0.02 & 0.53 & 0.97 & 1.06 \\
\hline RASi & 0.92 & 0.36 & 0.84 & 0.43 & 1.97 & 1.47 & 0.79 & 0.48 & 0.51 & 4.23 \\
\hline Statin & 1.22 & 0.47 & 0.60 & 0.57 & 2.61 & 1.09 & 0.54 & 0.85 & 0.42 & 2.85 \\
\hline DPP4i & 1.38 & 0.53 & 0.40 & 0.65 & 2.93 & 0.91 & 0.48 & 0.86 & 0.33 & 2.56 \\
\hline
\end{tabular}

DPP4i: Dipeptidyl peptidase-4 inhibitor, RASi: renin-angiotensin system inhibitor, UAE: urinary albumin excretion. 
Clinic), Dr. Ken-ichi Imamura (Imamura Clinic), Dr. Yoshifumi Umemura (Umemura Iin), Dr. Katsuhiro Okamoto (Okamoto Naika Iin), Dr. Naoko Kusumi and Dr. Eriko Ogura (Tokiwa-kai Hospital), Dr. Yoshihiko Kakisaka (Kakisaka Iin), Dr. Hideo Kakuta (Kakuta Geka Clinic), Dr. Yutaka Kanehira (Kanehira Clinic), Dr. Takashi Kudo (Kudo Naika Syonika Iin), Dr. Takeshi Kudo (Okidate Heart Clinic), Dr. Yoshihiko Sawada (Sawada Naika Iin), Dr. Masayuki Shimizu (Shimizu Clinic), Dr. Ken-ichi Shirato and Dr. Tasuku Shiroto (Hirosaki Chuo Hospital), Dr. Masahiko Tanaka (Tanaka Geka Naika Iin), Dr. Yuichi Tamada (Tamada Naika Iin), Dr Hironobu Chiba (Chiba Ichoka Naika Iin), Dr. Koji Fujimoto (Tsugaru General Hospital) and Dr. Seiichi Miyamoto (Kensei Hospital)

The authors would like to thank Enago (www.enago.jp) for the English language review and Kaze no An (www.medstatsupport.com) for the support of statistical analysis.

\section{References}

1 Gregg EW, Li Y, Wang J, Burrows NR, Ali MK, Rolka D, Williams DE and Geiss L: Changes in diabetes-related complications in the United States, 1990-2010. N Engl J Med 370: 1514-1523, 2014.

2 Parving HH, Lewis JB, Ravid M, Remuzzi G, Hunsicker LG and DEMAND investigators: Prevalence and risk factors for microalbuminuria in a referred cohort of type II diabetic patients: a global perspective. Kidney Int 69: 2057-2063, 2006.

3 Yokoyama H, Kawai K, Kobayashi M and Japan Diabetes Clinical Data Management Study Group: Microalbuminuria is common in Japanese type 2 diabetic patients: a nationwide survey from the Japan Diabetes Clinical Data Management Study Group (JDDM 10). Diabetes Care 30: 989-992, 2007.

4 Adler AI, Stevens RJ, Manley SE, Bilous RW, Cull CA, Holman RR and UKPDS Group: Development and progression of nephropathy in type 2 diabetes: The United Kingdom Prospective Diabetes Study (UKPDS 64). Kidney Int 63: 225232, 2003.

5 Japanese Society for Dialysis Therapy, Condition as of December 31, 2013. In: An Overview of Regular Dialysis Treatment in Japan, Japanese Society for Dialysis Therapy pp. 2-29, 2014 (in Japanese).

6 Gaede P, Vedel P, Parving $\mathrm{HH}$ and Pedersen O: Intensified multifactorial intervention in patients with type 2 diabetes mellitus and microalbuminuria: the Steno type 2 randomised study. Lancet 353: 617-622, 1999.

7 Gaede P, Vedal P, Larsen N, Jensen GV, Parving HH and Pedersen O: Multifactorial intervention and cardiovascular disease in patients with type 2 diabetes. N Engl J Med 348: 383 393, 2003

8 Araki S, Haneda M, Sugimoto T, Isono M, Isshiki K, Kashiwagi A and Koya D: Factors associated with frequent remission of microalbuminuria in patients with type 2 diabetes. Diabetes 54 : 2983-2987, 2005.
9 Gaede P, Oellgaard J, Carstensen B, Rossing P, Lund-Andersen $\mathrm{H}$, Parving $\mathrm{HH}$ and Pedersen $\mathrm{O}$ : Years of life gained by multifactorial intervention in patients with type 2 diabetesmellitus and microalbuminuria: 21 years follow-up on the Steno-2 randomised trial. Diabetologia 59: 2298-2307, 2016.

10 Japan Diabetes Society. Treatment Guide for Diabetes 2010 2011 (in Japanese).

11 Perkins BA, Ficociello LH, Silva KH, Finkelstein DM, Warram JH and Krolewski AS: Regression of microalbuminuria in type 1 diabetes. N Engl J Med 348: 2285-2293, 2003.

12 Giorgino F, Laviola L, Cavallo Perin P, Solnica B, Fuller J and Chaturvedi $\mathrm{N}$ : Factors associated with progression to macroalbuminuria in microalbuminuric Type 1 diabetic patients: the EURODIAB Prospective Complications Study. Diabetologia 47: 1020-1028, 2004.

13 Gaede P, Tarnow L, Vedel P, Parving HH and Pedersen O: Remission to normoalbuminuria during multifactorial treatment preserves kidney function in patients with type 2 diabetes and microalbuminuria. Nephrol Dial Transplant 19: 2784-2788, 2004.

14 Yamada T, Komatsu M, Komiya I, Miyahara Y, Shima Y, Matsuzaki M, Ishikawa Y, Mita R, Fujiwara M, Furusato M, Nishi $\mathrm{K}$ and Aizawa $\mathrm{T}$ : Development, progression, and regression of microalbuminuria in Japanese patients with type 2 diabetes under tight glycemic and blood pressure control. Diabetes Care 28: 2733-2738, 2005.

15 Katayama S, Moriya T, Tanaka S, Tanaka S, Yajima Y, Sone H, Iimuro S, Ohashi Y, Akanuma Y and Yamada $\mathrm{N}$ for the Japan Diabetes Complications Study Group: Low transition rate from normo- and low microalbuminuria to proteinuria in Japanese type 2 diabetic individuals: the Japan Diabetes Complications Study (JDCS). Diabetologia 54: 1025-1031, 2011.

16 Hsieh MC, Hsieh YiT, Cho TJ, Chen JF, Lin SD, Chen HC and Tu ST: Remission of diabetic nephropathy in type 2 diabetic Asian population: role of tight glucose and blood pressure control. Eur J Clin Invest 41: 870-878, 2011.

17 Avogaro A and Fadini GP: The effects of dipeptidyl peptidase-4 inhibition on microvascular diabetes complications. Diab Care 37: 2884-2894, 2014.

18 Fioretto P, Zambon A, Rossato M, Busetto L and Vettor R: SGLT2 inhibitors and the diabetic kidney. Diab Care 39(suppl 2): S165-S171, 2016. 